Journal of Chromatography, 336 (1984) 241-248

Biomedical Applications

Elsevier Science Publishers B.V., Amsterdam - Printed in The Netherlands

CHROMBIO. 2317

\title{
RAPID AND SELECTIVE DERIVATIZATION METHOD FOR THE NITROGEN-SENSITIVE DETECTION OF CARBOXYLIC ACIDS IN BIOLOGICAL FLUIDS PRIOR TO GAS CHROMATOGRAPHIC ANALYSIS
}

\author{
H. LINGEMAN, H.B.P. HAAN and A. HULSHOFF*
}

Pharmaceutical Laboratory, Department of Analytical Pharmacy, State University of Utrecht, Catharijnesingel 60,3511 GH Utrecht (The Netherlands)

(Received May 11th, 1984)

\section{SUMMARY}

A rapid and selective derivatization procedure is described for the pre-column labelling of carboxylic acids with a nitrogen-containing label. The carboxylic acid function is activated with 2-bromo-1-methylpyridinium iodide and the activated carboxylic acid function reacts with a primary or a secondary amine to yield an amide. With flurbiprofen as the test compound and dipropylamine as a label the acid was completely converted to the corresponding amide. The method was tested for several aliphatic, aromatic and for phenylacetic or phenylpropionic carboxylic acid derivatives, and was found to result in the complete derivatization of these compounds with a few exceptions only. The derivatization procedure is potentially useful for drug monitoring purposes, as is shown with the analysis of valproic acid and flurbiprofen in plasma.

\section{INTRODUCTION}

A number of derivatization methods have been described for derivatization of carboxylic acids, in order to improve the chromatographic behaviour and/or to lower the detection limit in gas chromatographic (GC) systems [1]. Alkylation with different types of alkyl halides such as methyl iodide [2], butyl iodide [3, 4], phenacyl bromide [5] or pentafluorobenzyl bromide [6, 7] as derivatization reagent is the most widely used method for the GC determination of compounds with a carboxylic acid function. In some cases other alkylation reagents such as diazomethane [8] or diazopropane [9], or silylation reactions [10] are used. None of these reagents is selective for the carboxylic acid function. Many carboxylic acids, including therapeutically important compounds, depend for a sensitive GC analysis on detectororientated derivatization techniques. Methods aimed at improved detection 
with the nitrogen-phosphorus thermionic detector are scarce in the literature.

Schulz and Vilceanu [11] described the reaction with dimethyl- $\alpha$-hydroxymethanephosphonate, but this reagent is not easily accessible. In the present study the application of a selective derivatization reaction [12] for the sensitive detection of compounds with a carboxylic acid function is investigated. The method is based on the formation of an amide by coupling the acid with simple aliphatic amines (e.g. dipropylamine or diethylamine).

\section{EXPERIMENTAL}

\section{Materials}

Butylamine, dibutylamine, dipropylamine, ethylamine, ninhydrin and propylamine, all gold-label quality, were obtained from Janssen Chimica (Beerse, Belgium). Diethylamine, 2-bromopyridine and methyl iodide came also from Janssen Chimica. Benzoic acid, sorbic acid and triethylamine came from E. Merck (Darmstadt, F.R.G.), naproxen from UCB (The Hague, The Netherlands) and flurbiprofen from Boots (Vianen, The Netherlands). Sodium valproate was obtained from Albic (Maassluis, The Netherlands). Acetonitrile, chloroform, dichloromethane, diethyl ether, dimethylformamide, hexane, methanol and toluene, all analytical-reagent grade, were purchased from J.T. Baker (Deventer, The Netherlands) and were distilled from glass before use. The methanol for GLC analysis was obtained from Mallinckrodt (St. Louis, MO, U.S.A.) as nanograde quality. The other compounds used in this study came from various sources or were obtained as gifts from various companies and used as such.

2-Bromo-1-methylpyridinium iodide (BMP) was synthesized following the procedure described by Saigo et al. [13] for the synthesis of 2-chloro-1-methylpyridinium iodide.

The amide of dipropylamine and flurbiprofen (FbDPA) was synthesized on a preparative scale. Purification of the reaction product was performed with thinlayer (TLC) and column chromatography. The resulting product was recrystallized twice from ethanol and stored over phosphorus pentoxide. Its identity was conformed by infrared spectrometry and mass spectrometry.

\section{Gas chromatography}

Two gas-liquid chromatographic (GLC) systems were used. System I consisted of an Intersmat IGC 16 (Intersmat Instruments, Pavillons sous Bois, France) equipped with dual flame-ionization detectors. The glass columns $(2 \mathrm{~m}$ $\times 1.8 \mathrm{~mm}$ I.D.) were packed with $3 \%$ OV-17 on 100-120 mesh Chromosorb W HP (Chrompack, Middelburg, The Netherlands). The carrier gas (nitrogen) flowrate was $20 \mathrm{ml} / \mathrm{min}$, the hydrogen flow-rate $30 \mathrm{ml} / \mathrm{min}$ and the air flow-rate $300 \mathrm{ml} / \mathrm{min}$. The injection port and detector temperatures were $290^{\circ} \mathrm{C}$ and $330^{\circ} \mathrm{C}$, respectively.

System II consisted of a Hewlett-Packard HP 5710 A (Hewlett-Packard, Avondale, PA, U.S.A.) equipped with a dual nitrogen-phosphorus flameionization detector, Model 18789 A (Hewlett-Packard). The glass column (1.4 $\mathrm{m} \times 1.9 \mathrm{~mm}$ I.D.) was packed with $3 \%$ SP-1000 on 100-120 mesh Chromosorb W HP (Chrompack). The carrier gas (nitrogen) flow-rate was 52 
$\mathrm{ml} / \mathrm{min}$, the hydrogen flow-rate $3.8 \mathrm{ml} / \mathrm{min}$ and the air flow-rate $50 \mathrm{ml} / \mathrm{min}$. The injection port and detector temperatures were $300^{\circ} \mathrm{C}$.

\section{Thin-layer chromatography}

TLC plates (E. Merck) of $5 \times 10 \mathrm{~cm}$ and $20 \times 20 \mathrm{~cm}$, precoated with silica gel $60 \mathrm{~F}$ and a layer thickness of $0.25 \mathrm{~mm}$, were used. Reactions were performed in solutions originally containing $10 \mu \mathrm{g}$ of carboxylic acid and were analysed by spotting an aliquot of these reaction mixtures on the plate together with solutions of the acid under investigation and the reagent mixtures, respectively. The plates were developed in the ascending mode with eluents consisting of chloroform-methanol or chloroform-hexane mixtures. After evaporation of the eluent the spots were vizualized under ultraviolet radiation of $254 \mathrm{~nm}$ or by spraying with a $10 \%$ solution of ninhydrin in ethanol.

\section{DERIVATIZATION PROCEDURES}

\section{$B M P$ method $A$}

To $10 \mu \mathrm{l}$ of a solution of $0.01-1.0 \mu \mathrm{g}$ of carboxylic acid in dichloromethane in a $1.5-\mathrm{ml}$ polypropylene tube, also containing a suitable internal standard, 10 $\mu \mathrm{l}$ of BMP solution $(10 \mu \mathrm{g} / \mu \mathrm{l}$ in acetonitrile $), 20 \mu \mathrm{l}$ of dipropylamine solution (label) $(10 \mu \mathrm{g} / \mu \mathrm{l}$ in dichloromethane), $60 \mu \mathrm{l}$ of dichloromethane and $10 \mu \mathrm{l}$ of acetonitrile were added. After vortex mixing for $15 \mathrm{sec}$ the mixture was allowed to stand for $5 \mathrm{~min}$ at $5^{\circ} \mathrm{C}$. Then $500 \mu \mathrm{l}$ of dichloromethane were added and the mixture was extracted three times with $500 \mu \mathrm{l}$ of $2 \mathrm{M}$ sulphuric acid. The organic phase was transferred to another polypropylene tube and evaporated to dryness under a stream of nitrogen. The residue was dissolved in $20 \mu 1$ of methanol; $1-\mu 1$ portions of the resulting solutions were injected into the chromatograph.

\section{$B M P$ method $B$}

To $10 \mu \mathrm{l}$ of a solution of $1-10 \mu \mathrm{g}$ of carboxylic acid in dichloromethane, acetonitrile or dimethylformamide, $30 \mu \mathrm{l}$ of a BMP solution $(10 \mu \mathrm{g} / \mu \mathrm{l}$ in acetonitrile) and $40 \mu \mathrm{l}$ of a solution of the label $(10 \mu \mathrm{g} / \mu \mathrm{l}$ in dichloromethane) were added. After vortex mixing for $15 \mathrm{sec}$ the mixture was allowed to stand for $15 \mathrm{~min}$ at room temperature. For TLC analysis the mixture was evaporated to dryness under a stream of nitrogen. The residue was dissolved in $50 \mu \mathrm{l}$ of methanol and $10 \mu \mathrm{l}$ were spotted on a thin-layer plate. For GLC analysis the mixture was extracted with sulphuric acid and further processed as described under BMP method $A$.

\section{RESULTS AND DISCUSSION}

\section{The derivatization procedure}

Flurbiprofen, unless mentioned otherwise, was used as a test compound in the derivatization studies with simple aliphatic primary or secondary amines. The derivatization procedure is based on activation of the carboxylic acid function with BMP [12]. Without activating either the carboxylic acid or the amine (reagent) function only minute amounts of the amide are formed under 
the mild reaction conditions used in this study. Instead of an amine reagent it is also possible to use a primary alcohol as the reagent [12] .

The BMP method as described above was developed by us, based on the work of Saigo et al. [13]. In the BMP method the reaction is base catalysed. However, it was not necessary to add a base (e.g. triethylamine) to the mixture because of the alkaline reaction of the label (e.g. dipropylamine, diethylamine) itself.

In Table I the influence of the solvent on the derivatization yield is summarized. Because BMP is insoluble in many organic solvents but soluble to a concentration of $10 \mu \mathrm{g} / \mu \mathrm{l}$ in acetonitrile, this BMP solution was used in combination with the other solvents of Table I. Dipropylamine was used as the label and derivatization method $B$ was used. The derivatization yield was measured by comparison of the peak height ratio of the amide, FbDPA, and the amide of the internal standard (naproxen), which was purified in the same way as described for the purification of FbDPA in this paper, after GLC analysis (system II). Furthermore, the disappearance of flurbiprofen in the derivatization mixture was followed by means of TLC analysis and GLC analysis (system I).

In Table II the influence of the choice of the label on the derivatization yield is summarized. In some cases (e.g. methylamphetamine), it was necessary to add triethylamine, as a base catalyst, to the reaction mixture to achieve $100 \%$ conversion to the amide. If simple aliphatic primary or secondary amines

\section{TABLE I}

INFLUENCE OF THE SOLVENT ON THE DERIVATIZATION YIELD

\begin{tabular}{llll}
\hline Solvent & BMP method A & Solvent & BMP method A \\
\hline Acetonitrile & + & Dimethylformamide & + \\
Butyronitrile & + & Hexane & $+1-$ \\
Chloroform & $+1-$ & Methanol & - \\
Dichloromethane & + & Pyridine & - \\
Diethyl ether & - & Toluene & $+1-$ \\
\hline
\end{tabular}

${ }^{\star}+=$ reaction is quantitative, $+/-=$ reaction takes place, but is not quantitative, $-=$ reaction does not take place.

\section{TABLE II}

INFLUENCE OF THE LABEL ON THE DERIVATIZATION YIELD

\begin{tabular}{llll}
\hline Label & BMP method B & Label & BMP method B \\
\hline 1,3-Diallyl-6-aminouracil & - & Ethylamine & + \\
6-Amino-1,3-dimethyluracil & - & Diethylamine & + \\
Amphetamine & + & Propylamine + \\
N-Methylamphetamine & + & Dipropylamine & + \\
4-Aminoantipyrine & - & Butylamine & + \\
Guanidine & - & Dibutylamine + \\
Guanine & - & Tributylamine & - \\
\hline
\end{tabular}

$\star_{+}=$reaction is quantitative, $-=$reaction does not take place. 
(second column of Table II) were used it was never necessary to add base to the mixture. The tertiary amine tributylamine did not react, as expected. The use of a secondary amine in the derivatization reaction is to be preferred to the use of a primary amine, because of the almost two-fold increase in response of the nitrogen-phosphorus detector observed with the former.

A number of other compounds with carboxylic acid functions and some compounds with other acidic functions were tested. The reaction mixtures were investigated by TLC and GLC (system II) analysis with a programmed oven temperature from $100^{\circ} \mathrm{C}$ to $270^{\circ} \mathrm{C}\left(10^{\circ} \mathrm{C} / \mathrm{min}\right)$. The appearance of a new spot in the thin-layer chromatogram and/or a new peak in the gas chromatogram, together with the disappearance of the acid spot in the thin-layer chromatogram were considered as evidence for conversion of the acid under investigation into the corresponding amide. The complete disappearance of the acid spot from the TLC chromatogram and the absence of the acid peak in the GLC chromatogram (system I) indicated that at least $90 \%$ of the acid had been converted. In all cases reagent blanks were analysed. Almost all of the carboxylic acids thus tested were completely converted to the corresponding amide. Phthalic acid, a dicarboxylic acid, and gallic acid, a carboxylic acid containing three phenolic functions, did not yield detectable amounts of derivatives. The results are summarized in Table III. The compounds with

TABLE III

DERIVATIZATION OF DIFFERENT ACIDIC FUNCTIONS ${ }^{\star}$

\begin{tabular}{llllll}
\hline Compound & TLC & GLC & Compound & TLC & GLC
\end{tabular}

1a. Aliphatic carboxylic acids

$\begin{array}{llc}\text { Acetic acid } & 0 & +1- \\ \text { Lauric acid } & 0 & + \\ \text { Myristic acid } & 0 & + \\ \text { Sorbic acid } & + & + \\ \text { Stearic acid } & 0 & + \\ \text { Valproic acid } & 0 & +\end{array}$

2. Aromutic carboxylic acids

$\begin{array}{lcc}\text { Benzoic acid } & + & + \\ \text { Nalidixic acid } & + & 0 \\ \text { Nicotinic acid } & + & + \\ \text { Phthalic acid } & - & - \\ \text { Probenecid } & + & +\end{array}$

1b. Aliphatic carboxylic acids with aromatic groups

Diclufenac
Flurbiprofen
Ibuprofen
Indomethacin
Naproxen
Phenylacetic acid

$\begin{array}{ll}+ & + \\ + & + \\ + & + \\ + & 0 \\ + & +\end{array}$

3. Carboxylic acids with other acidic or basic functions

$\begin{array}{lll}m \text {-Aminobenzoic acid } & + & 0 \\ \text {-Aminocaproic acid } & + & 0 \\ \text { Gallic acid } & - & - \\ \text { Salicylic acid } & +/- & +/- \\ p \text {-Sulphamoyl benzoic acid } & + & 0\end{array}$

4. Compounds with other (than carboxylic) acidic functions

$\begin{array}{lll}\text { Barbituric acid } & - & - \\ \text { Mercaptopurine } & - & - \\ \text { Phenol } & - & - \\ \text { Purine } & - & - \\ \text { Salicylamide } & - & - \\ \text { Sulphanilic acid } & - & -\end{array}$

${ }^{\star}+=$ reaction is quantitative, $+/-=$ reaction takes place, but is not quantitative, $-=$ reaction does not take place, $0=$ derivative not detectable with the chosen chromatographic system. 
acidic functions other than the carboxylic acid function were not derivatized to any detectable degree with this method (Table III).

For subsequent GLC studies a mixture of dichloromethane-acetonitrile was used as the solvent and simple aliphatic secondary amines as labels (BMP method A). The amount of BMP added to the mixture was reduced and the influence of the reaction temperature was investigated. The reaction between flurbiprofen and dipropylamine, performed under the conditions described under $B M P$ method $A$, was completed within 2 min at $5^{\circ} \mathrm{C}$. This high reaction rate, even at low temperatures, is an important advantage over many other derivatization reactions, particularly in the case of thermolabile compounds. The reaction could also be performed at room temperature with satisfactory results, but at higher temperatures lower reaction yields were obtained.

\section{GLC analysis}

Representative chromatograms from the GLC analysis (system II, column temperature $255^{\circ} \mathrm{C}$ ) of the derivatization mixtures, obtained after reacting flurbiprofen and naproxen (internal standard) with dipropylamine by BMP method A, are shown in Fig. 1. Instead of 3\% SP-1000, it was also possible to use $3 \%$ OV -17 or $10 \%$ Carbowax $20 \mathrm{M}+2 \%$ potassium hydroxide as the stationary phase. The detection limit of the amide (FbDPA) was about $60 \mathrm{pg}$ with a signal-to-noise ratio of 2 . To test the reproducibility of the method nine samples containing $1 \mu \mathrm{g}$ of flurbiprofen were derivatized following the procedure proposed above. The mean value and the relative standard deviation

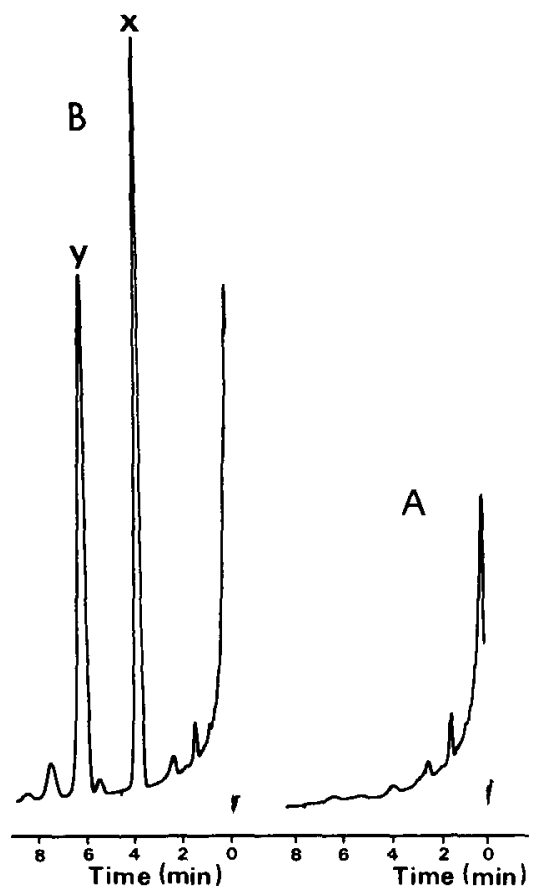

Fig. 1. Chromatograms obtained after derivatization of flurbiprofen with dipropylamine. (A) Reagent blank; (B) chromatogram after derivatization of $0.5 \mu \mathrm{g}$ of flurbiprofen and $0.5 \mu \mathrm{g}$ of naproxen following BMP method $A . x=F b D P A ; y=$ dipropylaminenaproxate. 
of the peak height ratio of FbDPA and the amide of the internal standard were $1.60 \%$ and $3.8 \%$, respectively.

The usefulness of the procedure in quantitative analysis was further tested by the analysis of benzoic acid after reaction with diethylamine as label and sorbic acid as the internal standard. GLC system II was used with $10 \%$ Carbowax $20 \mathrm{M}+2 \%$ potassium hydroxide as the stationary phase. After an isothermal period of $6 \mathrm{~min}$ at $175^{\circ} \mathrm{C}$ the oven temperature was programmed to rise by $31^{\circ} \mathrm{C} / \mathrm{min}$ to $240^{\circ} \mathrm{C}$. The retention times of the amides of benzoic acid and sorbic acid were 348 and $262 \mathrm{sec}$, respectively.

The calibration curve showed good linearity; $Y=0.02( \pm 0.01)+1.08( \pm$ $0.02) X(r=0.997)$ was the equation for the calibration line after analysing ten samples containing $0.1-1.0 \mu \mathrm{g}$ of benzoic acid, $Y$ and $X$ being the peak height ratio of the benzoic acid and sorbic acid peaks and the benzoic acid concentration $(\mu \mathrm{g} / \mu \mathrm{l})$, respectively. The numbers in parentheses are the standard deviations.

\section{Analysis of flurbiprofen and sodium valproate in plasma samples}

The potential usefulness of the derivatization with secondary amines for the analysis of carboxylic acids in blood plasma was investigated with flurbiprofen, an analgesic anti-inflammatory drug, and with sodium valproate, an anticonvulsant drug, as test compounds.

Plasma samples of $50 \mu \mathrm{l}$, spiked with $0.1-1.0 \mu \mathrm{g}$ of sodium valproate and 0.5 $\mu \mathrm{g}$ of sorbic acid as the internal standard were acidified with $10 \mu \mathrm{l}$ of $4 \mathrm{M}$ hydrochloric acid and then extracted with $250 \mu \mathrm{l}$ of chloroform. After $1 \mathrm{~min}$ vortex-mixing and $5 \mathrm{~min}$ centrifugation $(2500 \mathrm{~g})$ the aqueous layer was discarded; the chloroform layer was transferred to a clean vial and evaporated to dryness under a stream of nitrogen. The residue was derivatized according to

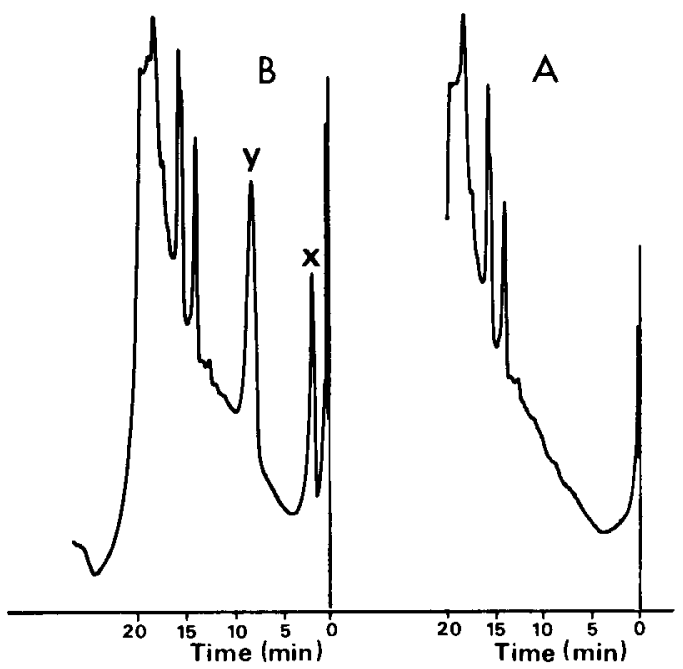

Fig. 2. Chromatograms obtained after extraction of sodium valproate from plasma and

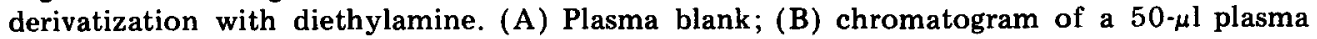
sample containing $0.01 \mu \mathrm{g} / \mu \mathrm{l}$ valproate and $0.01 \mu \mathrm{g} / \mu \mathrm{l}$ sorbic acid subjected to BMP method A. $x=$ diethylaminevalproate $; y=$ diethylaminesorbate. 
BMP method A with diethylamine, and of the final solution $1 \mu \mathrm{l}$ was subjected to GLC analysis (system II). After an isothermal period of $4 \mathrm{~min}$ at $125^{\circ} \mathrm{C}$, the oven temperature was programmed to rise by $10^{\circ} \mathrm{C} / \mathrm{min}$ to $270^{\circ} \mathrm{C}$. The equation for the calibration line was $Y=-0.08( \pm 0.04)+2.04( \pm 0.07) X(r=$ $0.995, n=8$ ). A blank plasma sample was treated in the same way. Chromatograms are shown in Fig. 2.

The second application was the analysis of flurbiprofen in plasma. A plasma sample of $50 \mu \mathrm{l}$, containing $0.05-0.5 \mu \mathrm{g}$ of flurbiprofen and $0.5 \mu \mathrm{g}$ of naproxen as internal standard, was acidified with $10 \mu \mathrm{l}$ of $4 M$ hydrochloric acid and extracted with $200 \mu$ l of dichloromethane. After 1 min vortex-mixing and 5 min centrifugation $(2500 \mathrm{~g})$ the aqueous layer was discarded and the dichloromethane layer was transferred to a clean vial and evaporated to dryness under a stream of nitrogen. The residue was derivatized with diethylamine according to BMP method $\mathrm{A}$ and $1 \mu \mathrm{l}$ of the final solution was subjected to GLC analysis (system II) with an isothermal oven temperature of $255^{\circ} \mathrm{C}$. The equation for the calibration line was $Y=-0.01( \pm 0.01)+2.28( \pm 0.05) X$ $(r=0.998, n=8)$.

\section{ACKNOWLEDGEMENT}

The authors are indebted to Miss H.M. van Mastbergen for her assistance with the experimental work.

\section{REFERENCES}

1 D.R. Knapp, Handbook of Analytical Derivatization Reactions, Wiley, New York and Chichester, 1979, pp. 146-224.

2 W. Schneider and P.H. Degen, J. Chromatogr., 217 (1981) 263.

3 H. Roseboom, R.H.A. Sorel, H. Lingeman and R. Bouwman, J. Chromatogr., 163 (1979) 92.

4 A. Hulshoff and A.D. Förch, J. Chromatogr., 220 (1981) 275.

5 N.J. Cook and D.A. Jowett, J. Chromatogr., 272 (1983) 181.

6 R.G. Sibeon, J.D. Baty, N. Baber, K. Chan and M. L'E. Orme, J. Chromatogr., 153 (1978) 189.

7 W. Stueber, E. Mutschler and D. Steinbach, J. Chromatogr., 227 (1982) 193.

8 K. Kawahara, M. Matsumura and K. Kimura, J. Chromatogr., 223 (1981) 202.

9 A. Arbin, J. Chromatogr., 144 (1977) 85.

10 F.S. Abbott, R. Burton, J. Orr, D. Wladichuk, S. Ferguson and T.-H. Sun, J. Chromatogr., 227 (1982) 433.

11 P. Schulz and R. Vilceanu, J. Chromatogr., 111 (1975) 105.

12 H. Lingeman, A. Hulshoff, W.J.M. Underberg and F.B.J.M. Offermann, J. Chromatogr., $290(1984) 215$.

13 K. Saigo, M. Usui, K. Kikuchi, E. Shimada and T. Mukaiyama, Bull. Chem. Soc. Jap., 50 (1977) 1863. 